\title{
Mapping Land Use and Land Cover in the Upper Ciliwung Watershed Using Landsat Tree Cover (TC) Data
}

\author{
Hildanus $^{\text {a }}$, Suria Darma Tarigan ${ }^{\text {b, }}$, Kukuh Murtilaksono ${ }^{\mathrm{b}}$, Baba Barus ${ }^{\mathrm{b}}$ \\ ${ }^{a}$ Natutal Resources and Environment Management, Bogor Agriculture University, Bogor, Indonesia \\ ${ }^{b}$ Soil Science and Natural Resources, Bogor Agriculture University, Bogor, Indonesia \\ Corresponding author: ${ }^{*}$ suriatarigan2014@gmail.com
}

\begin{abstract}
Land use and land cover (LULC) mapping using Landsat Tree Cover (TC) data that we employed was digital classification by converting Landsat TC raster data into Landsat TC vector data and determining LULC classes in the attribute table based on percent TC criteria (interval TC- min - TC-max). The classification was adapted from the LCCS classification and partially modified. Compared to conventional digital image classification (supervised and unsupervised classifications), our digital classification method is easier and faster because Landsat TC data does not require pre-processing and reclassification to improve classification accuracy. Landsat TC classification accuracy was assessed against the interpretation of a very high spatial resolution (VHSR) image available in Google Earth (GE). The purpose of the study was to determine the ability of Landsat TC data paired with percent TC criteria of LULC adapted from the LCCS classification and validated with VHSR in GE for mapping LULC in the tropics. This study was conducted in the Upper Ciliwung watershed, which is located in Bogor Regency, West Java Province, Indonesia. LULC mapping using Landsat TC data paired with percent TC criteria of LULC adapted from the LCCS classification and validated with VHSR in GE provided a useful tool for producing LULC map in the Upper Ciliwung watershed. This study classified LULC in the Upper Ciliwung watershed consisting of settlements, closed forests, medium forests, opened forests, mix gardens, tea plantations, shrub lands, grasslands, and rainfed croplands paddy fields, fish fonds, and bare lands with overall accuracy of $91 \%$.
\end{abstract}

Keywords-Landsat TC; LCCS classification; percent tree cover; Google Earth; upper Ciliwung watershed.

\section{INTRODUCTION}

Tree canopy cover is an important measure of forest health and productivity and is used in applications such as climate change mitigation, forest management, and pest and disease monitoring [1]. Tree cover data can provide a baseline for developing management plans, setting longitudinal forest monitoring [2]. TC is one of the simplest ways to assess the area of urban forests and the benefits of urban forests [3]. TCC is an acceptable measure for urban forests because it is relatively fast, easy to obtain, and cost-effective [4].

The available percent tree cover products on a global or continental scale are few, and efforts to quantitatively validate these maps have been limited [5],[6]. Validating percent tree cover maps is limited to some regions or countries because it is difficult to obtain reference data or field data, and the sampling method affects the estimation of map accuracy [5].

Among the various satellite data types, optical satellite is the main data source for characterizing $\mathrm{TC}$ and detecting changes in TC due to the large availability of data [7]. Optical satellite imagery with a medium spatial resolution (MSR), e.g., Landsat, is preferred for mapping and monitoring large areas over a time scale of several decades while maintaining a relatively high level of spatial detail and minimizing data acquisition costs [8]. Spatial resolution of MSR is 10-100 m [9],[10]. The Landsat satellite series have provided datasets with consistent MSR since Landsat-1 launched in 1972 [11],[7].

The free and open access to Landsat imageries systematically collected and archived by NASA and the USGS [12] has fostered the use of Landsat data to address innumerable science questions [13]. Landsat archive provides the longest data record with rigorous geometric and radiometric calibrations and continuity guaranteed well into the future [14]. Open access policy to Landsat datasets is becoming the norm and is necessary to maximize the societal benefits from satellite data [11]. Global Landsat TC continuous fields map has been generated by Sexton et al. [15] 
was facilitated by the opening of the Landsat archive, but its accuracy has not been comprehensively evaluated [7].

In order to percent tree cover map, Sexton et al. [5] and Kobayashi [6] referred to the percent ground surface area covered by a vertical projection of the foliage and branches of trees when the leaves were at full growth. Small openings inside each crown were included in percent TC, or 'percent crown cover' was used for 'percent TC'.

In this study, LULC mapping was carried out in the Upper Ciliwung watershed, Bogor Regency, Province West Java, Indonesia, using RS technical. The Landsat TC continuous fields data was prepared by the University of Maryland's Global Land Cover Facility (GLCF; www.landcover.org) [16] available globally for free and used in this study. This data contains percent tree cover information on grids for a land area of $30 \times 30 \mathrm{~m}^{2}$ and is the most detailed global percent TC data available to date. This data has not been evaluated comprehensively [7], including evaluation of its use in tropical areas, which is rarely reported, so it is interesting to study. To classify LULC, the percent TC criteria were used. The TC criteria for the LULC classes used are the LCCS classification, which is used by [5] for the use of MODIS data. The classification accuracy is calculated against the interpretation results of images obtained from Google Earth (GE). High spatial resolution, HSR $(\leq 30 \mathrm{~m})$ image [17], in GE has been used as reference dataset for validating classification image in recent years [6], [16], [18], [19]. The use of reference datasets collected from the interpretation of HSR images has been replacing field-based reference datasets, and this trend will continue [20]. In the practice of visual image interpretation, VHSR images should be prioritized [21]. Spatial resolution of VHSR image is $<1 \mathrm{~m}$ [17].

The purpose of the study was to determine the ability of Landsat TC data paired with percent TC criteria of LULC adapted from the LCCS classification and validated with VHSR-image in GE for LULC mapping in the Upper Ciliwung Watershed in Bogor Regency, West Java Province, Indonesia.

\section{MATERIALS AND METHOD}

Data used in the study are as follows:

- Landsat TC Version 4 Path-Row 122-065-pixel 30m in 2000, 2005, 2010, and 2015 were downloaded from www.landcover.org. The Landsat TC raster data digitally classified for producing LULC-2015 map;

- Image with pixel $0.6 \mathrm{~m}$ in 2015 downloaded in Google Earth (GE), and the GE-image interpreted visually as a reference to determine LULC classes and accuracy assessment of Landsat TC classification;

- Rupa Bumi Indonesia (RBI) map in 2010 and scale 1:25000, downloaded from http://tanahair.indonesia.go.id and used to registration of all digital images and reference for GE-image interpretation;

- The Upper Ciliwung watershed boundaries map resulting from DEM delineation, used to clip RBI map, GE-image, and Landsat TC data. The tool used a computer installed with image processing, geographic information system (GIS), and Google Earth software.

This study consisted of five stages, namely:
- Data preparation (clipping of map and images, and registration);

- LULC-2015 mapping by visual interpretation of GEimage with pixels $0.6-\mathrm{m}$ in 2015 ;

- LULC-2015 mapping by digital classification of Landsat TC-2015;

- Accuracy assessment of Landsat TC classification.

\section{A. Data Preparation: Clipping and Registration}

Registration aims to synchronize the coordinate system and datum of all spatial data used in this study (image from GE, Landsat TC data, and RBI map). Thus, certain locations have almost the same coordinates on all spatial data. In this registration process, the RBI map is used as a reference.

Before registration was carried out, the coordinate system and datum of all spatial data were equalized, and then all spatial data were clipped roughly outside the study area boundary. The datum used is WGS 84 , and the coordinate system is UTM $48 \mathrm{~S}$, where $48 \mathrm{~S}$ is the zone of the Upper Ciliwung Watershed (study site) located-clipping all spatial data before registration is useful for speeding up the registration process.

\section{B. Visual Interpretation of Image from Google Earth}

Visual interpretation of images from GE is carried out by identifying and delineating land uses based on interpretation elements. Land use class refers to the RBI-2010 map with a scale of 1: 25000, where land uses in the Upper Ciliwung Watershed are Dryland forests, plantations], rainfed croplands; paddy fields, settlement, shrubs, grasslands, lakes-ponds, and rivers. In this study, the plantations were divided into mixed gardens and plantations (tea plantations). In the Upper Ciliwung Watershed, there is no lake, and hereinafter lakesponds are called ponds.

In order to speed up the on-screen digitization process in visual image interpretation, the RBI map is edited by updating its polygons based on the appearance of the image. For forest areas and land use rights (HGU) of tea plantations, which both areas have legal boundaries, editing the polygon of the boundaries of the two areas must be as accurate as possible.

The procedures for visual interpretation of VHSR image in GE are as follows:

- Image downloaded from Google Earth needs to be georeferenced using GIS software.

- Although using the same GIS tool, the georeferenced image is visually interpreted by identifying land use based on the interpretation key and delineated by digitizing it on the screen. The delineation process refers to the land use classes on the RBI map 1:25000 scale, by editing and updating the map based on the appearance of the image used. In addition to LULC in the RBI, fishponds that are also found in the Ciliwung Hulu watershed are also included in the LULC classes.

- (c) When interpreting imagery using GIS software, the same image can also be displayed in 2 or 3 dimensions $(2 \mathrm{D} / 3 \mathrm{D})$ in Google Earth and display symbols and information in Google Earth to help identify LULC in the image.

GE-image interpretation result is used as a reference to determine LULC classes and to assess the accuracy of Landsat TC classification. The reference for determining the 
LULC is vector of interpretation of the GE-image pixel of 0.6 $\mathrm{m}$, while the reference for assessing classification accuracy is the vector of the GE-image pixel of $30 \mathrm{~m}$ (same as the Landsat pixel size). This data is obtained by converting and resampling vector of interpretation of GE-image pixel of 0.6 $\mathrm{m}$ into a $30 \mathrm{~m}$ raster, then the resulting data is converted back into a vector. Although the pixel size and the number of LULC classes in the two vectors (the result of interpretation of the GE-image pixel $30 \mathrm{~m}$ and the result of the Landsat TC classification) are the same, the number of pixels (area of each LULC) of the two datasets is different, so the difference between the two datasets can be used to assess classification accuracy.

\section{Digital classification of Landsat TC data}

The procedure for mapping LULC through digital classification of Landsat TC data is: (a) Landsat TC raster data is downloaded in full scene, then the data is clipped outside the Upper Ciliwung watershed boundary using the watershed boundary map as a reference. (b) The clipped Landsat TC raster data is registered, as described in data preparation. (c) Landsat TC raster data converted to vector. (d) The Landsat TC vector is clipped to the Upper Ciliwung watershed boundary resulting from the DEM delineation (this stage is described in our other paper). (e) The LULC classes are determined based on the TC criteria of the Land Cover Classification System (LCCS) classification, summarized by [18], which they use it in the LULC mapping using MODIS data. In this study, the TC criteria from the LCCS classification were taken only for LULC in the Upper Ciliwung watershed, as presented in Table 1.

TABLE I

TC MINIMUM AND MAXIMUM BASED ON UN LCCS CLASSIFICATION FOR LAND USES IN UPPER CILIWUNG WATERSHED

\begin{tabular}{|c|c|c|c|}
\hline \multirow{2}{*}{ No } & \multirow{2}{*}{ Legend*) } & \multicolumn{2}{|c|}{$\% \mathrm{TC}$} \\
\hline & & Min & Max \\
\hline 1 & $\begin{array}{l}\text { Post-flooding or irrigated croplands (or } \\
\text { aquatic) }\end{array}$ & 0 & 20 \\
\hline 2 & Rainfed croplands & 0 & 20 \\
\hline 3 & $\begin{array}{l}\text { Closed ( }>40 \% \text { ) broadleaved deciduous } \\
\text { forest }\end{array}$ & 40 & 100 \\
\hline 4 & $\begin{array}{l}\text { Closed ( }>40 \%) \text { needle leaved evergreen } \\
\text { forest }\end{array}$ & 40 & 100 \\
\hline 5 & $\begin{array}{l}\text { Open }(15-40 \%) \text { broadleaved deciduous } \\
\text { forest/woodland }\end{array}$ & 15 & 40 \\
\hline 6 & $\begin{array}{l}\text { Open }(15-40 \%) \text { needle leaved } \\
\text { deciduous or evergreen forest }\end{array}$ & 15 & 40 \\
\hline 7 & $\begin{array}{l}\text { Mosaic forest or shrubland (50 - } \\
70 \%) / \text { grassland }(20-50 \%)\end{array}$ & 0 & 70 \\
\hline 8 & $\begin{array}{l}\text { Mosaic grassland }(50-70 \%) / \text { forest or } \\
\text { shrubland }(20-50 \%)\end{array}$ & 0 & 50 \\
\hline 9 & $\begin{array}{l}\text { Closed to open }(<15 \%) \text { grassland, } \\
\text { savannas or lichens } / \text { mosses }\end{array}$ & 0 & 15 \\
\hline 10 & Bare lands & 0 & 3 \\
\hline 11 & Urban areas $(>50 \%)$ & 0 & 3 \\
\hline 12 & Water bodies & 0 & 3 \\
\hline
\end{tabular}

\section{Landsat TC classification accuracy}

Accuracy was assessed using an error matrix. Error matrix is a cross-tabulation of the class labels predicted by the image classification against those from the reference dataset. The main problem in generating a valid error matrix is the collection of adequate and appropriate reference data [22]. All four standard accuracy assessment metrics are overall accuracy, user's acc., producer's acc., and kappa [20].

\section{RESULTS AND DISCUSSION}

\section{A. Landsat TC Characteristics}

Landsat TC raster data has 1 band with pseudo color as shown in Fig. 1.
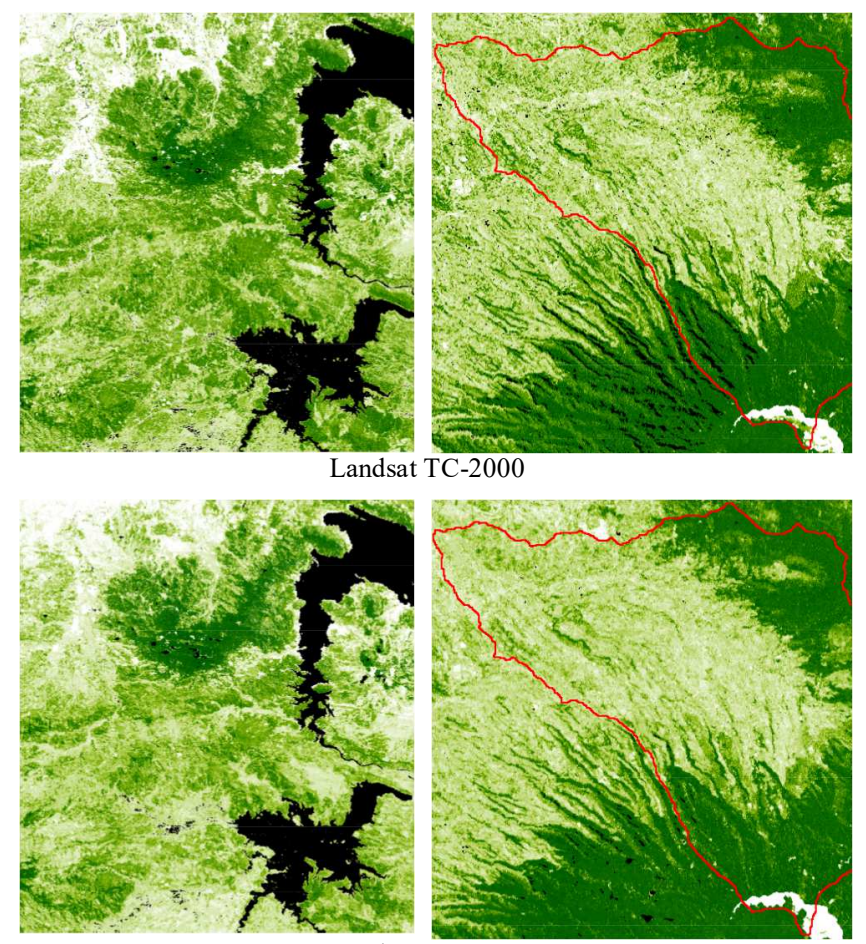

Landsat TC-2005
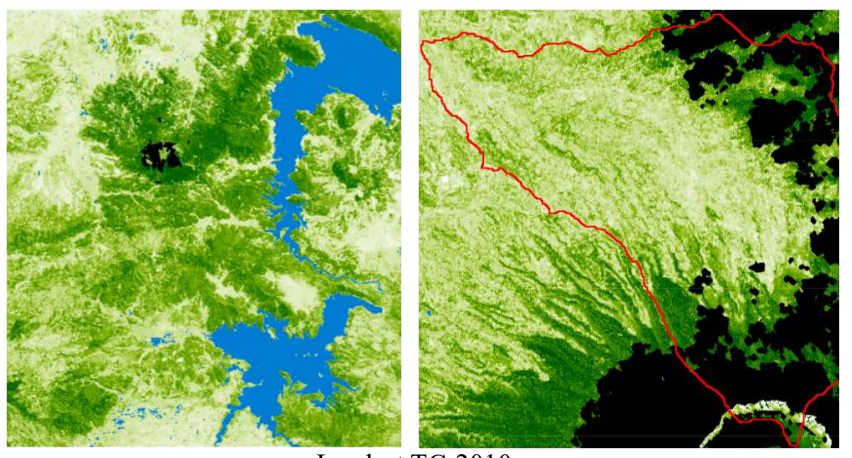

Landsat TC-2010

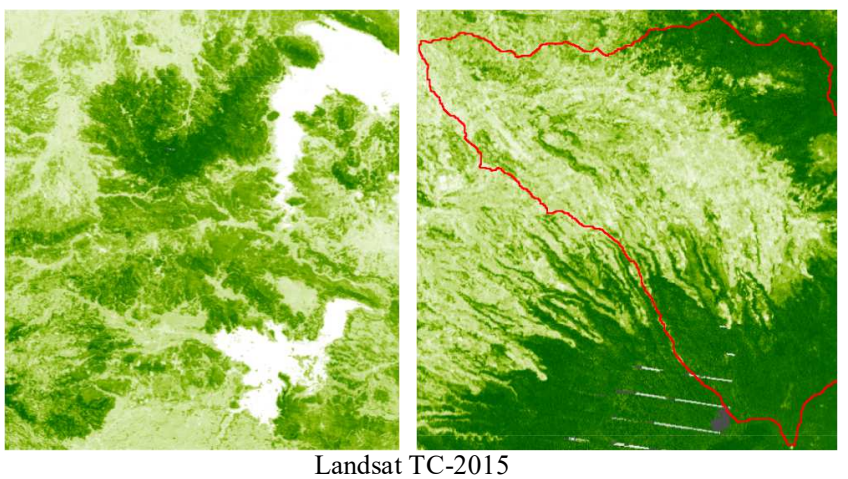

Fig. 1 Landsat TC raster data for 2000, 2005, 2010, and 2015 recording the Jatiluhur and Cirata Reservoirs and the Upper Ciliwung Watershed boundary 
The color gradation of the Landsat TC raster data is from the brightest indicates areas with minimum vegetation (i.e., settlements or water bodies) to dark green indicating areas with maximum vegetation (i.e., closed forest). In the Landsat $\mathrm{TC}$ raster data, there is no TC value, but they can be found in the results of converting Landsat TC raster data into vector data. The raster to vector conversion produces an attribute table, where the Landsat $\mathrm{TC}$ vector attribute table contains a grid code with values varying from 0 to $100,200,210,211$, and 220, depending on the tree canopy cover included in the Landsat data. 0 to 100 provide information on the percent tree cover for a land area of $30 \mathrm{mx} 30 \mathrm{~m}$. A value of 200 represents water bodies, 210 represents clouds, 211 represents shadows, and 220 represents filled values.

In Fig. 1, there are two reservoirs in the image on the left, namely Jatiluhur Reservoir (object above) and Cirata Reservoir (object below). In the right images, the red line at Landsat TC is the boundary of the Upper Ciliwung Watershed. The reservoirs are black on Landsat TC in 2000 and 2005, blue on Landsat TC-2010, and white on Landsat TC-2015. The value of the water bodies in the reservoir is 200 in Landsat TC in 2000, 2005, and 2010, and 0 in Landsat TC in 2015. Although it is inconsistent in stating the water bodies, the two values (200 and 0 ) are included in the TC criteria for expressing water bodies in Table 2. In the Landsat TC in 2000 and 2005, white color on the Southeastern part of the Upper Ciliwung Watershed is a part of the mountain peak identified as an area without vegetation (bare land) with the TC value is 0 . In the Landsat TC-2015, white lines in the Northern part of the watershed come from striping in Landsat raw data, with a TC value of 220. Black color in Landsat TC-2010 is a combination of cloud cover (TC is 210) and cloud shadows (TC is 211).

\section{B. The LCCS Classification}

The LCCS classification classified water bodies, bare lands, urban and built-up land with TC minimum (TC-min) $=0$ and $\mathrm{TC}$ maximum $(\mathrm{TC}-\max )=3$, or $0 \leq \mathrm{TC} \leq 3$. $\mathrm{TC}$ criteria for closed to open $(<15 \%)$ grasslands are TC-min $=0$ and TC$\max =15$ or $0 \leq \mathrm{TC} \leq 15$. Irrigated croplands and rainfed croplands are classified with criteria TC-min $=0$ and TC-max $=20$ or $0 \leq \mathrm{TC} \leq 20$. Forests are classified with $2 \mathrm{TC}$ criteria: open forest $(15 \leq \mathrm{TC} \leq 40)$ and closed forest $(40 \leq \mathrm{TC} \leq 100)$. The TC criteria for mosaic cropland $(50-70 \%)$ with vegetation (grassland, shrubland, forest) $(20-50 \%)$ is $0 \leq \mathrm{TC}$ $\leq 50$, while the TC criteria for mosaic vegetation (grassland, shrubland, forest) $(50-70 \%)$ with cropland $(20-50 \%)$ is $0 \leq$ $\mathrm{TC} \leq 70$.

\section{TC Criteria Used in This Study}

1) Water Bodies (Rivers and Ponds): In this study, water bodies (rivers and ponds) were determined using the same TC criteria as the LCCS classification, namely $0 \leq \mathrm{TC} \leq 3$, then also entering the value 200 , where this value for representing water bodies on the Landsat TC data. However, based on the author's experienced in identifying LULC, the value 200 does not necessarily indicate water bodies. By comparing between the Landsat TC vector and the vector of GE-image interpretation, with the acquisition year of the two data being the same, it was found that the value of 200 in the Landsat TC vector showed water bodies (rivers, ponds), paddy fields inundated water, and also topographical shadows in forest areas. Furthermore, using the value 200 in the Landsat TC data as a criterion for water bodies is recommended to use VHSR image for the same acquisition year as a comparison in classifying Landsat TC.

2) Paddy Fields Inundated Water and Fish Pond: The TC criteria for irrigated croplands in the LCCS classification, namely $0 \leq \mathrm{TC} \leq 20$, is also used for paddy fields. Paddy fields criteria is also used for fish ponds criteria. LCCS does not classify fish ponds, and criteria suitable for fish ponds are the paddy fields criteria, where these criteria give producer acc. $\geq$ $85 \%$ for fish ponds. However, when the water bodies criteria are used for fish ponds, the producer acc. has not yet reached $85 \%$.

3) Grasslands and Bare Lands: The TC criteria for grasslands in this study used the TC criteria for closed to open $(<15 \%)$ herbaceous vegetation (grasslands, savannas or lichens/mosses) in the LCCS classification, namely $0 \leq \mathrm{T} \leq$ 15. The grasslands criteria also used for bare lands.

4) Rainfed croplands: The TC criteria for rainfed croplands used the rainfed croplands criteria in the LCCS classification, namely $0 \leq \mathrm{TC} \leq 20$.

5) Settlement: This study's TC criteria for settlement are 0 $\leq \mathrm{TC} \leq 20$, much more different from the TC criteria for urban areas $>50 \%, 0 \leq \mathrm{TC} \leq 3$ in the LCCS classification. The TCmax value for settlement is determined based on try and error, which is the selected value determined based on the producer acc. When the settlement criteria equating with the TC criteria for grasslands $(0 \leq \mathrm{TC} \leq 15)$, producer acc. has not reached $85 \%$ yet. PA settlement $\geq 85 \%$ for TC-max $\leq 20$.

6) Forests: Unlike the LCCS classification which divided forest into 2 groups, open and closed forests, in this study the forests were divided into three groups based on BSN (2010). BSN, Badan Standar Nasional (National Standardization Body), determined the Indonesian National Standard (SNI) for the land cover classification. In the SNI Classification, forests are grouped into closed forest (> 70\% density), medium forest ( $41-70 \%$ density), and open forest (10 - 40\% density). In this study, the TC criteria for open forest was 16 $<\mathrm{TC} \leq 40$, medium forest was $41<\mathrm{TC} \leq 70$, and closed forest was $71<\mathrm{TC} \leq 100$.

7) Shrublands: Mosaic of grassland (50-70\%) with forest or shrubland $(20-50 \%)$ in the LCCS classification with the $\mathrm{TC}$ criteria $0 \leq \mathrm{TC} \leq 50$ was used for shrubland criteria in this study and modified to $16<\mathrm{TC} \leq 50$.

8) Mixed Garden and Plantation. In this study, mosaic of forest or shrubland $(50-70 \%)$ with grassland $(20-50 \%)$ in the LCCS classification with the TC criteria $0 \leq \mathrm{TC} \leq 70$ was used for mixed garden and plantation criteria and modified to $16<\mathrm{TC} \leq 70$.

The TC criteria (interval TC- min - TC-max) used in study adapted from the LCCS classification and partially modified are shown in Table 2. 
TABLE II

TC CRITERIA (INTERVAL TC-MIN - TC-MAX) ADAPTED FROM THE LCCS CLASSIFICATION AND PARTIALLY MODIFIED

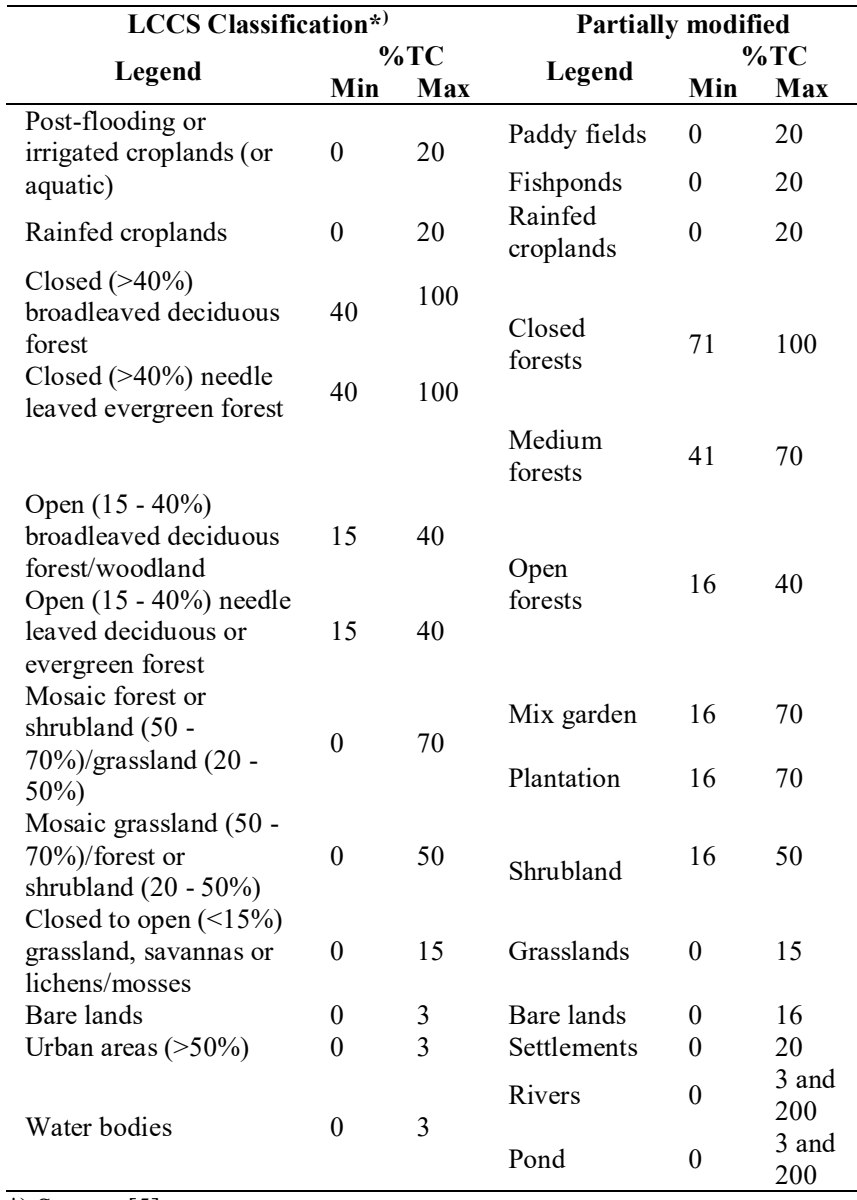

*) Source: [5].

\section{Accuracy Assessment}

Accuracy assessment is assessed in an error matrix by comparing the vector of the Landsat TC classification and vector of the image interpretation in GE as a reference.
Reference was used with the same pixel size as the Landsat TC pixel size, which is $30 \mathrm{~m}$, as described in the research methodology.

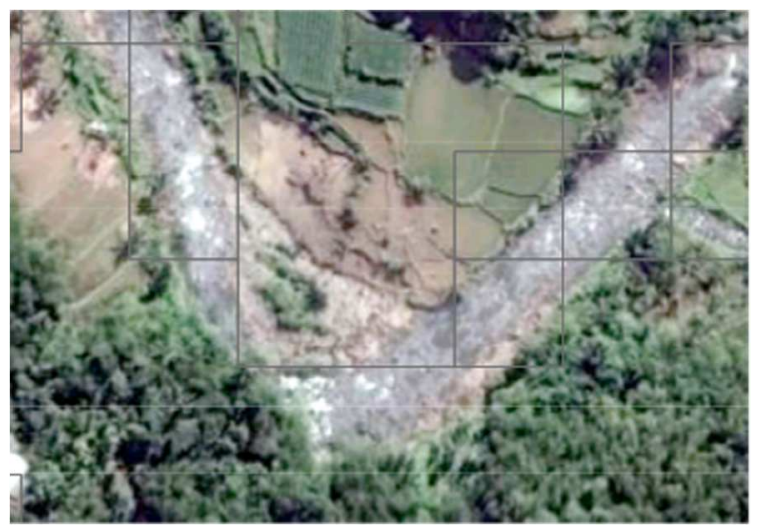

(a) River channel opened from canopy cover and showed stone and gravel

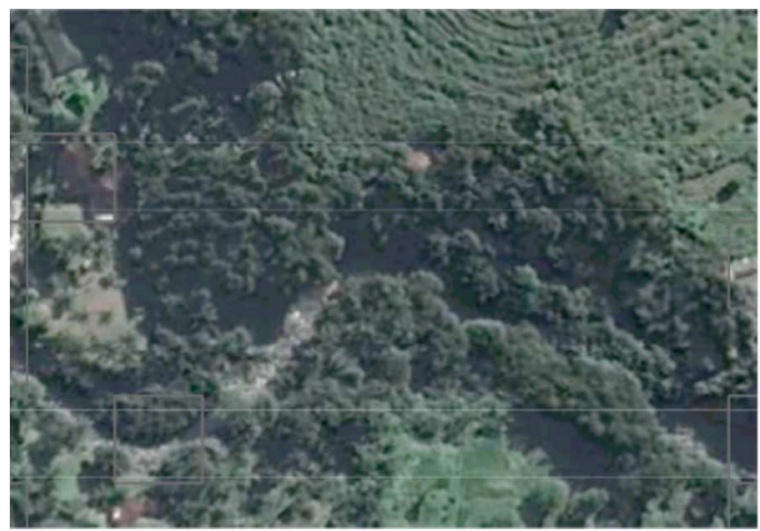

(b) River channel partially closed by canopy cover

Fig. 2 A partial view of the river channel in the Upper Ciliwung watershed on a GE-image pixel $0.6 \mathrm{~m}$ in 2015

In Table 3, it is shown that the water bodies (rivers and lakes) in the Upper Ciliwung Watershed have a PA of 0. This suggests that the Landsat TC data cannot classify water bodies

TABLE III

ERROR MATRIX FOR CALCULATING THE ACCURACY OF LANDSAT TC ClASSIFICATION AGAINST THE RESULTS OF INTERPRETATION OF IMAGE FROM GE

\begin{tabular}{|c|c|c|c|c|c|c|c|c|c|c|c|c|c|c|c|c|}
\hline \multirow{2}{*}{$\begin{array}{l}\text { Land uses area in } \\
\text { Landsat TC (Ha) }\end{array}$} & \multicolumn{14}{|c|}{ Land uses area in GE (Ha) } & \multirow{2}{*}{$\begin{array}{l}\text { Total } \\
\text { Rows }\end{array}$} & \multirow{2}{*}{$\begin{array}{l}\text { User's } \\
\text { Acc. }\end{array}$} \\
\hline & GI & OF & $\mathbf{C F}$ & MF & MG & RC & Pt & St & PF & SL & $\mathbf{P}$ & $\mathbf{R v}$ & FP & Bl & & \\
\hline Grassland (Gl) & 15.3 & 0.0 & 0.0 & 0.0 & 0.0 & 0.0 & 0.0 & 0.0 & 0.0 & 0.0 & 0.0 & 0.0 & 0.0 & 0.0 & 15.3 & 100.0 \\
\hline Open Forest (OF) & 0.0 & 14.4 & 3.7 & 6.1 & 0.0 & 0.0 & 0.0 & 2.6 & 0.0 & 0.0 & 0.0 & 0.0 & 0.0 & 0.0 & 26.8 & 53.7 \\
\hline Closed Forest (CF) & 0.0 & 0.3 & 3522.9 & 26.1 & 0.0 & 0.0 & 0.0 & 0.1 & 0.0 & 0.0 & 0.0 & 0.0 & 0.0 & 0.0 & 3549.3 & 99.3 \\
\hline Medium Forest (MF) & 0.0 & 1.8 & 643.9 & 228.9 & 0.0 & 0.0 & 0.0 & 2.4 & 0.0 & 0.0 & 0.0 & 0.0 & 0.0 & 0.0 & 877.0 & 73.4 \\
\hline Mix Garden (MG) & 0.5 & 0.0 & 0.0 & 0.0 & 3331.9 & 396.9 & 0.0 & 0.0 & 33.7 & 0.0 & 2.1 & 44.4 & 0.3 & 0.5 & 3810.3 & 87.4 \\
\hline Rainfed Cropland (RC) & 2.3 & 0.0 & 0.0 & 0.0 & 0.0 & 2132.3 & 0.0 & 0.0 & 0.0 & 0.0 & 0.0 & 0.0 & 0.0 & 4.2 & 2138.9 & 99.7 \\
\hline Plantation $(\mathrm{Pt})$ & 0.0 & 0.0 & 0.0 & 0.0 & 0.0 & 0.0 & 1387.1 & 0.0 & 0.0 & 0.0 & 0.0 & 0.0 & 0.0 & 0.0 & 1387.1 & 100.0 \\
\hline Settlement (St) & 0.0 & 0.0 & 0.0 & 0.0 & 0.0 & 0.0 & 0.0 & 1641.8 & 0.0 & 0.0 & 0.0 & 0.0 & 0.0 & 0.0 & 1641.8 & 100.0 \\
\hline Paddy Field (PF) & 0.0 & 0.0 & 0.0 & 0.0 & 0.0 & 0.0 & 0.0 & 0.0 & 254.4 & 0.0 & 0.0 & 0.0 & 0.0 & 0.0 & 254.4 & 100.0 \\
\hline Shrubland (SL) & 0.0 & 0.0 & 0.0 & 0.0 & 0.0 & 0.0 & 0.0 & 0.0 & 0.0 & 267.9 & 0.0 & 0.0 & 0.0 & 0.0 & 267.9 & 100.0 \\
\hline Pond (P) & 0.0 & 0.0 & 0.0 & 0.0 & 0.0 & 0.0 & 0.0 & 0.0 & 0.0 & 0.0 & 0.0 & 0.0 & 0.0 & 0.0 & 0.0 & 0.0 \\
\hline River (Rv) & 0.0 & 0.0 & 0.0 & 0.0 & 0.0 & 0.0 & 0.0 & 0.0 & 0.0 & 0.0 & 0.0 & 0.0 & 0.0 & 0.0 & 0.0 & 0.0 \\
\hline Fish Pond (FP) & 0.0 & 0.0 & 0.0 & 0.0 & 0.0 & 0.0 & 0.0 & 0.0 & 0.0 & 0.0 & 0.0 & 0.0 & 4.0 & 0.0 & 4.0 & 100.0 \\
\hline Bare land $(\mathrm{Bl})$ & 0.0 & 0.3 & 0.2 & 0.0 & 43.8 & 0.0 & 33.3 & 0.0 & 0.0 & 5.9 & 5.4 & 11.2 & 0.0 & 30.3 & 130.3 & 23.3 \\
\hline Total Column & 18.1 & 16.7 & 4170.6 & 261.1 & 3375.7 & 2529.3 & 1420.4 & 1646.9 & 288.1 & 273.9 & 7.5 & 55.5 & 4.3 & 35.1 & 14103.2 & \\
\hline Prod. Acc. & 84.6 & 86.0 & 84.5 & 87.7 & 98.7 & 84.3 & 97.7 & 099.7 & 88.3 & 97.8 & 0.0 & 0.0 & 91.7 & 86.4 & & \\
\hline
\end{tabular}

As a comparison, a large water bodies near the Upper Ciliwung Watershed, namely Jati Luhur and Cirata Reservoirs (see Fig. 1), has been attempted to be classified. For the TC value of the water bodies $0 \leq \mathrm{TC} \leq 3$ and 200 , the $\mathrm{PA} \geq 85 \%$ was obtained. But in Landsat TC in 2015, the river in the Upper Ciliwung Watershed was shallow, showing rocks in the river channel, and part of the river channel was covered by vegetation, so that most of the river channel were classified as mixed gardens and some were classified as bare lands. This can be shown by image in 2015 from GE with a spatial resolution of 0.6 meters with the true colors as shown in Fig. 2. Likewise, pond, where the edge of the pond is overgrown 
with vegetation, is classified as a mixed garden. The classification accuracy is expected to obtain an overall accuracy $(\mathrm{OA}) \geq 85 \%$.

Although the water bodies (rivers and ponds) have PA and UA is $0 \%$, and UA for bare lands, open forests, and medium forests is far below $85 \%$, but OA is $91 \%$. This is because the total area of water bodies, open land, sparse forest, and the medium forest is very small compared to other land uses in the Upper Ciliwung Watershed. The study conducted by [19] for mapping using Landsat $\mathrm{TC}$ data and GE-image as reference dataset also obtained an accuracy of above 87 . The use of pixel-based reference datasets tends to have higher accuracy than studies using field-based reference datasets but larger sample sizes [20].

\section{E. Advantages of LULC Mapping Using Landsat TC}

LULC mapping that we have done is by digital classification, by converting Landsat TC raster data (without geomatic and radiometric corrections) into vector data and determining LULC classes in the attribute table based on TC criteria (TC-min - TC-max intervals) of the LCCS classification. This digital classification method is easier and faster and does not require reclassification to improve accuracy compared to conventional digital classification. In conventional digital classification, LULC classes are determined by classifying reflectance values in the spectral bands of satellite data either by supervised or unsupervised classifications, in which some satellite data also requires geometric and radiometric corrections (pre-processing). Unlike the Landsat TC data, because this data is derived data (processed results) that have also undergone pre-processing when creating Landsat TC data, the use of this data no longer requires geometric corrections and radiometric corrections. The use of Landsat TC data for LULC mapping does not go through the "training area" to determine LULC classes and reclassification to improve classification accuracy as is done in traditional digital classifications, but only classifies percent TC values according to TC-min - TC-max intervals for LULC criteria and without reclassification.

As a criterion for distinguishing LULC in remote sensing data, tree canopy cover (TCC) is better than canopy cover (CC) of general vegetation for several reasons, namely: (1) Trees are older than other vegetation, so when ground check in the field, the possibility of the TCC changes shown on the image is smaller than that of the CC. (2) Vegetation canopy cover is generally used to distinguish LULC in conventional remote sensing from reflectance values in spectral bands or by vegetation index. The weakness is that the reflectance of the canopy cover of different vegetation types can appear almost the same, and the reflectance of the vegetation canopy cover can also be influenced by the reflectance of the soil (background) under the canopy.

The TC grouping in the Landsat TC data for TC $=16-40$, $\mathrm{TC}=41-70$, and TC $>70$ can classify forests into 3 densities: open forest, medium forest, and closed forest. Distinguishing these three forest densities requires a lot of effort and time when done by conventional digital classification or digitizing on-screen, even though using VHSR images (e.g., Quickbird$0,6 \mathrm{~m}$, IKONOS-1m).

\section{F. Disadvantages of LULC Mapping Using Landsat TC}

In this study, the TC criteria for land use in land use mapping with Landsat TC data modify the TC criteria for land use with MODIS data used by [5]. Some of the TC criteria for land use are exactly the same, and some of the criteria overlap. Thus, if we rely only on Landsat TC data, then land uses with the same TC criteria cannot be differentiated, and land uses with overlapping TC criteria have low Producer Acc. To distinguish between rice fields, rainfed agricultural land, and settlements that have the same TC criteria, the assistance of maps or another image is needed. It is easy to change the overlapping TC criteria (interval TC-min - TC-max) based on try and error, until obtained high Producer Acc., but this needs to be assured whether the TC interval for the land use criterion meets the definition of land use based on the percent tree cover. For this purpose, further research is suggested.

\section{CONCLUSION}

The LULC mapping using Landsat Tree Cover (TC) raster data that we have done is digital classification, by converting Landsat TC raster data into vector data and determining the LULC classes in the attribute table based on TC criteria (interval TC- min - TC-max) adapted from the LCCS classification and partially modified. Compared to conventional digital image classification (supervised and unsupervised classification), our digital classification method is easier and faster because Landsat TC data does not require pre-processing and reclassification to improve classification accuracy. The classification accuracy is assessed against the results of interpretation of VHSR-image in Google Earth. LULC mapping using Landsat TC raster data paired with percent TC criteria of LULC adapted from the LCCS classification and validated with VHSR-image in GE provided a useful tool for producing LULC map in the Upper Ciliwung watershed. This method can classify LULC in the Upper Ciliwung watershed consisting of settlements, closed forests, medium forests, opened forests, mix gardens, tea plantations, shrub lands, grasslands, and rainfed croplands paddy fields, fish fonds, and bare lands with overall accuracy $91 \%$.

\section{ACKNOWLEDGMENT}

The authors are grateful to the GLCF that permitted to download Landsat Tree Cover (TC) data. Also, we thank the Geospatial Information Agency (BIG) for the permission to download the 1: 25000 RBI map.

\section{REFERENCES}

[1] J. M. Derwin, V. A. Thomas, R. H. Wynne, J. W. Coulston, G. C. Liknes, S. Bender, C. E. Blinn, E. B. Brooks, B. Ruefenacht, R. Benton, M. V Finco, and K. Megown, "Int J Appl Earth Obs Geoinformation Estimating tree canopy cover using harmonic regression coefficients derived from multitemporal Landsat data," Int J Appl Earth Obs Geoinf., vol. 86, no. February 2019, p. 101985, 2020, doi: 10.1016/j.jag.2019.101985.

[2] J. A. Ejares, R. R. Violanda, A. G. Diola, D. T. Dy, J. B. Otadoy, R. E. S. Otadoy, C. Sciences, E. Group, and V. Leeuwen, "Tree Canopy Cover Mapping Using Lidar in Urban Barangays of Cebu City, Central Philippines," Int. Arch. Photogramm. Remote Sens. Spat. Inf. Sci., vol. XLI, no. July, pp. 611-615, 2016, doi: 10.5194/isprsarchivesXLI-B8-611-2016.

[3] D. J. Nowak and E. J. Green, "Urban Forestry \& Urban Greening Declining urban and community tree cover in the United States," 
Urban For. Urban Green., vol. 32, no. February, pp. 32-55, 2018, doi: 10.1016/j.ufug.2018.03.006.

[4] K. J. Doick, A. Buckland, and T. Clarke, "Historic Urban Tree Canopy Cover of Great Britain," forests, 2020.

[5] T. Kobayashi and R. Tateishi, "Comparison of a New Percent Tree Cover Dataset with Existing One and Categorical Land Cover Datasets in Eurasia," Adv. Remote Sens., vol. 2013, no. December, pp. 345-357, 2013.

[6] T. Kobayashi, J. Tsend-ayush, and R. Tateishi, "A new global treecover percentage map using MODIS data," Int. J. Remote Sens., vol. 1161, no. February, 2016, doi: 10.1080/01431161.2016.1142684.

[7] X. P. Song, H. Tang, and T. Cover, "Accuracy Assessment Of Landsat-Derived Continuous Fields of Tree Cover Products Using Airborne Lidar Data in The Eastern United," Int. Arch. Photogramm. Remote Sens. Spat. Inf. Sci., vol. XL, 2015, doi: 10.5194/isprsarchivesXL-7-W4-241-2015.

[8] M. Karlson, M. Ostwald, H. Reese, J. Sanou, B. Takoano, and E. Matsson, "Mapping Tree Canopy Cover and Aboveground Biomass in Sudano-Sahelian Woodlands Using Landsat 8 and Random Forest," Remote Sens., pp. 10017-10041, 2015, doi: 10.3390/rs70810017.

[9] F. Gao, M. Anderson, C. Daughtry, and D. Johnson, "Assessing the Variability of Corn and Soybean Yields in Central Iowa Using High Spatiotemporal Resolution Multi-Satellite Imagery," Remote Sens., 2018, doi: 10.3390/rs10091489.

[10] D. Frantz, A. Röder, M. Stellmes, and J. Hill, "Remote Sensing of Environment Phenology-adaptive pixel-based compositing using optical earth observation imagery," Remote Sens. Environ., vol. 190, pp. 331-347, 2017, doi: 10.1016/j.rse.2017.01.002.

[11] Z. Zhu, M. A. Wulder, D. P. Roy, C. E. Woodcock, M. C. Hansen, V. C. Radelo, S. P. Healey, C. Schaaf, P. Hostert, P. Strobl, J. Pekel, L. Lymburner, N. Pahlevan, and T. A. Scambos, "Remote Sensing of Environment Bene fi ts of the free and open Landsat data policy," Remote Sens. Environ., vol. 224, no. January, pp. 382-385, 2019, doi: 10.1016/j.rse.2019.02.016.

[12] M. A. Wulder, N. C. Coops, D. P. Roy, J. C. White, M. A. Wulder, N. C. Coops, D. P. Roy, and J. C. White, "Land cover 2.0," Int. J. Remote Sens., vol. 39, no. 12, pp. 4254-4284, 2018, doi: 10.1080/01431161.2018.1452075.

[13] M. A. Wulder, T. R. Loveland, D. P. Roy, C. J. Crawford, G. Masek, C. E. Woodcock, R. G. Allen, M. C. Anderson, A. S. Belward, W. B. Cohen, J. Dwyer, A. Erb, F. Gao, P. Gri, D. Helder, T. Hermosilla, J.
D. Hipple, P. Hostert, M. J. Hughes, et al., "Remote Sensing of Environment Current status of Landsat program, science, and applications," Remote Sens. Environ., vol. 225, no. February, pp. 127147, 2019, doi: 10.1016/j.rse.2019.02.015.

[14] Hadi, A. Krasovskii, V. M. P. Yogawarna, S. Pietsch, and M. Rautiainen, "Monitoring Deforestation in Rainforests Using Satellite Data : A Pilot Study from Kalimantan , Indonesia," forests, pp. 1-26, doi: 10.3390/19070389.

[15] J. O. Sexton, X. Song, M. Feng, P. Noojipady, C. Huang, D. Kim, K M. Collins, C. Dimiceli, J. R. Townshend, J. O. Sexton, X. Song, M. Feng, P. Noojipady, C. Huang, D. Kim, K. M. Collins, and S. Channan, "Global , 30-m resolution continuous fields of tree cover: Landsatbased rescaling of MODIS vegetation continuous fields with lidarbased estimates of error," Int. J. Digit. Earth, vol. 6, no. 5, pp. 427448, 2013, doi: 10.1080/17538947.2013.786146.

[16] P. M. Montesano, C. S. R. Neigh, J. Sexton, M. Feng, S. Channan, K. J. Ranson, and J. R. Townshend, "Calibration and Validation of Landsat Tree Cover in the Taiga ' Tundra Ecotone," Remote Sens., pp. 5-7, 2016, doi: 10.3390/rs8070551.

[17] J. Miettinen, C. Shi, and S. C. Liew, "Towards automated $10-30 \mathrm{~m}$ resolution land cover mapping in insular South-East Asia," Geocarto Int., vol. 6049, no. December, pp. 1-15, 2017, doi: 10.1080/10106049.2017.1408700.

[18] S. Godinho, N. Guiomar, and A. Gil, "Estimating tree canopy cover percentage in a mediterranean silvopastoral systems using Sentinel-2A imagery and the stochastic gradient boosting algorithm," Int. J. Remote Sens., vol. 00, no. 00, pp. 1-23, 2017, doi: 10.1080/01431161.2017.1399480.

[19] A. Ahrends, P. M. Hollingsworth, P. Beckscha, H. Chen, R. J. Zomer, L. Zhang, M. Wang, and J. Xu, "China's fight to halt tree cover loss," Proceding R. Soc., pp. 1-10, 2017.

[20] L. Morales-barquero, M. B. Lyons, S. R. Phinn, and C. M. Roelfsema, "Trends in Remote Sensing Accuracy Assessment Approaches in the Context of Natural Resources," Remote Sens., pp. 1-16.

[21] Z. Asrat, H. Taddese, H. O. Ørka, T. Gobakken, and E. Næsset, "Estimation of Forest Area and Canopy Cover Based on Visual Interpretation of Satellite Images in Ethiopia," land, pp. 1-17, 2018, doi: 10.3390/land7030092.

[22] K. Yadav and R. G.Congakton, "Issues with Large Area Thematic Accuracy Assessment for Mapping Cropland Extent : A Tale of Three Continents," Remote Sens., 2018, doi: 10.3390/rs10010053. 